\title{
Highly pathogenic avian influenza h5n I persistence in Africa: household poultry perspective \& public health implications
}

\begin{abstract}
Highly Pathogenic Avian Influenza is an emerging zoonotic infection with wide host range, including man, it has affected twelve countries in Africa but endemic in Egypt; Nigeria and others have had infections and re-infections. Due to its zoonotic and reassortment potential HPAI H5N1 remains a major threat to human health. Household poultry (HHP) constitutes about $80 \%$ of poultry practice in Africa and is made up largely of indigenous breeds, mixed species are reared in same flock, biosecurity measures is poorly practiced, and it is in close proximity with human habitations; therefore HHP can facilitate $\mathrm{H} 5 \mathrm{~N} 1$ persistence and human infections. As at the end of 2015, Egypt had the highest number of confirmed human cases (346) across the globe with 116 deaths, and was traceable to HHP. Improved biosecurity measures and hygiene must be enforced at every level of poultry production, and poultry pens should be located far from residential houses.
\end{abstract}

Keywords: Africa, hpai, h5n1, persistence, hhp, public health
Volume 5 Issue 2 - 2017

\author{
Fasanmi Olubunmi Gabriel \\ Department of Production Animal Studies, University of \\ Pretoria, South Africa
}

Correspondence: Fasanmi Olubunmi Gabriel, Department of Production Animal Studies, Faculty of Veterinary Science, University of Pretoria, Onderstepoort 0I I0, South Africa, Tel +27 625047537, Email bumaetal@gmail.com

Received: August 25, 2016 | Published: March 27, 2017
Abbreviations: HHP, house hold poultry; HPAI, highly pathogenic avian influenza; OIE, world organisation for animal health

\section{Introduction}

The emergence of Highly Pathogenic Avian Influenza (HPAI) $\mathrm{H} 5 \mathrm{~N} 1$ from the Asian continent has led to the adaptation, evolution and hence the re-emergence of a re-assortant causal virus in Africa, first detected in Nigeria in $2006^{2,3}$ and subsequently reported in other 11 African countries. ${ }^{4}$ The rapid spread of HPAI H5N1 infection has led to the decimation of poultry population with negative attendant consequences on the sales of poultry and poultry products and economics of production..$^{5-7}$ Due to its zoonotic potential and ability for re-assortment HPAI H5N1 remains a major threat to human health in Africa; so far, Egypt has the highest number of confirmed human cases and reported case fatality across the globe. ${ }^{8,9}$

Analyses and comparative assessments of data of HPAI H5N1 outbreaks in poultry from 2006-2016 in Egypt, Nigeria and other African countries show a progressive increase in the number of outbreaks of H5N1 HPAI in poultry especially from 2006-2008 to the outbreaks of subsequent years (Table 1). ${ }^{10,11}$

\section{Household poultry}

The predisposing factors to the perpetuation and persistence of HPAI H5N1 in Africa are inexhaustible; but among the important factors strongly believed to facilitate $\mathrm{H} 5 \mathrm{~N} 1$ persistence and spread is household poultry (HHP), otherwise referred to as backyard or traditional poultry; this constitute about $80 \%$ of poultry stocks made up largely of indigenous breeds and various species mixed in the same flock and reared especially by semi intensive or extensive husbandry methods. ${ }^{12-14}$

HHP has become a common practice in most countries of Africa, especially Nigeria and Egypt, because it involves the rearing of multi- species of poultry (duck, turkey, pigeon, quail and chicken) and other livestock (pig, cane rat, rabbit, goat etc.), in close proximity with human habitations; and characterised by poor biosecurity measures; which has been proven to be an indispensable tool for the mitigation of the spread of infections. ${ }^{15-18}$ A recent study conducted shows that epidemiological dynamics of HPAI has changed, with the origins of majority of the outbreaks pointing towards household/backyard poultry and associated with human cases of $\mathrm{H} 5 \mathrm{~N} 1$ infections, ${ }^{19,20}$ this was further corroborated by OIE ${ }^{21}$ that HPAI H5N1 outbreaks in Nigeria between 2014-2016 has a significant number of the outbreaks in HHP

\section{Public health implications}

Due to the poultry husbandry method practiced in Africa and the nearness of its operations to residential houses, as at the end of 2015, Egypt had the highest number of confirmed human cases (346) across the globe with 116 deaths recorded, second to Indonesia, (Table 2). ${ }^{9}$ It is worrisome to observe that since the first HPAI H5N1 outbreak in Egypt in 2006, the cases, death and case fatality rate in poultry and humans continue to increase unabated. ${ }^{22-24}$

\section{Conclusion}

This is a reflection and a pointer towards the endemic state of HPAI H5N1 in Africa, and all these portend a bleak and elusive hope of controlling and eradicating the deadly viral sub-type in the continent of Africa. Therefore radical approach must be taken, especially in the area of applied practical Biosecurity and hygiene, active and passive surveillance, proper orientation and enlightenment of stake holders in poultry business and poultry houses must be located far from residential houses.

\section{Acknowledgements}

None. 


\section{Conflict of interest}

Author declares that there is no conflict of interest.

\section{References}

1. Li X, Zhang Z, Yu A, et al. Global and local persistence of influenza A(H5N1) virus. Emerg Infect Dis. 2014;20(8):1287-1295.

2. Joannis T, Lombin LH, De Benedictis P, et al. Confirmation of H5N1 avian influenza in Africa. Vet Rec. 2006;158(9):309-310.

3. Cattoli G, Monne I, Fusaro A, et al. Highly Pathogenic Avian Influenza Virus Subtype H5N1 in Africa: A Comprehensive Phylogenetic Analysis and Molecular Characterization of Isolates. PLoSONE. 2009;4(3):e4842.

4. Update on highly pathogenic avian influenza in animals (type H5 and H7). Followup report no. 50. OIE. 2017;1-17.

5. Rushton J, Viscarra R, Guerne-Bleich E, et al. Impact of avian influenza outbreaks in the poultry sectors of five south east asian countries (Cambodia, Indonesia, Lao PDR, Thailand and Vietnam): outbreak costs, responses and potential long-term control. 2005.

6. Fasina FO, Sirdar MM, Bisschop SPR. The financial cost implications of the highly pathogenic notifiable avian influenza H5N1 in Nigeria. Onderstepoort $J$ Vet Res. 2008;75(1):39-46.

7. Otte J, Hinrichs J, Rushton J, et al. Impacts of avian influenza virus on animal production in developing countries. CAB Reviews: PAVSNNR. 2008;3(80):1-18.

8. Kayali G, Webby RJ, Xiong X, et al. Prospective study of avian influenza transmission to humans in Egypt. BMC Public Health. 2010;10:685.

9. Total number of cases includes number of deaths; WHO reports only laboratory cases. WHO. 2015.

10. Lockhart C, Pittiglio C, Ingabire C, et al. H5N1 HPAI spread in Nigeria and increased risk for neighbouring countries in West Africa. FAO. 2015 $10 \mathrm{p}$

11. FAO. Global Animal Disease Intelligence Report. 2015;2:1-20.

12. Gueye EF. Gender aspects in family poultry management systems in developing countries. Worlds Poult Sci J. 2005;61(1):39-46.
13. Pym R, Guerne Bleich E, Hoffmann I. The relative contribution of indigenous chicken breeds to poultry meat and egg production and consumption in the developing countries of Africa and Asia. 12th European Poultry conference, Italy. World's Poult Sci Assoc. 2006. p. 197.

14. Sonaiya F. Smallholder family poultry as a tool to initiate rural development. International Conference Poultry in the Twenty-first Century: avian influenza and beyond. Bangkok, Thailand; 2008.

15. Dorea FC, Berghaus R, Hofacre C, et al. Surveys of Biosecurity protocols and practices adopted by growers on commercial poultry farms in Georgia, U.S.A. Avian Dis. 2010;54(3):1007-1015.

16. Julien D, Thompson S. Interactive methods to educate and engage poultry producers on the importance of practicing on-farm Biosecurity. $J$ Agric Ext Rural Dev. 2011;3(8):137-140.

17. Conan A, Goutard FL, Sorn S, et al. Biosecurity measures for backyard poultry in developing countries: a systematic review. BMC Vet Res. 2012;8:240.

18. Fasina FO, Ali AM, Yilma JM, et al. The cost-benefit of Biosecurity measures on infectious diseases in the Egyptian household poultry. Prev Vet Med. 2012;103(2-3):178-191.

19. Arafa A, Naguib M, Luttermann C, et al. Emergence of a novel cluster of influenza A (H5N1) virus clade 2.2. 1.2 with putative human health impact in Egypt. Euro Surveill. 2015;20(13):2-8.

20. Arafa A, El-Masry I, Khoulosy S, et al. Predominance and geo-mapping of avian influenza H5N1 in poultry sectors in Egypt. Geospat Health. 2016;11(3):492.

21. Update on highly pathogenic avian influenza in animals (type H5 and H7). World Organisation for Animal Health (OIE). 2016.

22. Human infection with avian influenza A (H5N1) virus, Egypt - first update. European Centre for Disease Prevention and Control. Stockholm, Sweden. 2015

23. Fasanmi OG, Laleye AT, Fasina FO. Systematic review and meta-analyses of cases and deaths associated with HPAI H5N1 in humans and poultry. CAB Reviews Perspectives in Agriculture Veterinary Science Nutrition and Natural Resources. 2016;11:004.

24. Cumulative number of confirmed human cases for avian influenza A(H5N1) reported to WHO. 2003-2015. 